\title{
Metodologias desenvolvidas pela genealogia intelectual da ciência da religião
}

\author{
Methodologies developed in the intellectual genealogy of study of \\ religions
}

Fábio L. Stern ${ }^{1}$

caoihim@gmail.com

Matheus Oliva da Costa ${ }^{2}$

matheusskt@hotmail.com

\begin{abstract}
Resumo: Esse texto demonstra como a ciência da religião é uma ciência autônoma e que seus pesquisadores construíram diversos métodos de pesquisar religiões, desde o seu surgimento no século XIX até a atualidade. Para isso, é realizada uma revisão bibliográfica com o recorte específico de autores que escreveram dentro de genealogias intelectuais da ciência da religião enquanto ciência autônoma. Quatro tipos de métodos são discutidos nesse texto: os principais modelos de pesquisa empírica, os métodos comparativos, os métodos classificatórios e a atitude metodológica frente ao objeto. Esse texto aponta à necessidade de cientistas das religiões no Brasil dominarem sua própria história e conhecerem as questões que envolvem seus debates metodológicos internacionais.
\end{abstract}

Palavras-chave: Metodologia científica. Pesquisa empírica. Métodos comparativos. Métodos classificatórios. Agnosticismo metodológico.

\begin{abstract}
This paper demonstrates that the study of religions is an autonomous science and that its researchers have constructed several methods of studing religions, from its birth in the 19th century to the present. For this, a bibliographic review is carried out with a specific selection of authors who have written within intellectual genealogies that describe the study of religion as an autonomous science. Four types of methods are discussed in this text: the main models for empirical research, the comparative methods, the classificatory methods, and the methodological attitude towards the object. This text points to the need for scholars of religion in Brazil to dominate its own history and to know the questions surrounding its international debates regarding methodology.
\end{abstract}

Keywords: Scientific methodology. Empirical research. Comparative methods. Classificatory methods. Methodological agnosticism.

\footnotetext{
${ }^{1}$ Doutorando em Ciência da Religião (PUC-SP), mestre em Ciência da Religião (PUC-SP), especialista em Ciências da Religião (PUC-SP), bolsista da CAPES.

${ }^{2}$ Doutorando em Ciência da Religião (PUC-SP), mestre em Ciência da Religião (PUC-SP), licenciado em Ciências da Religião (UNIMONTES), bolsista da CAPES.
} 


\section{INTRODUÇÃO}

Segundo Engler e Stausberg (2013, p. 63), métodos científicos são “técnicas para reunir e analisar dados na pesquisa científica”. A história da ciência da religião mostra uma pluralidade de métodos surgidos dentro de uma genealogia intelectual de seus próprios cientistas. Entretanto, tem se tornado comum uma opinião corrente de que a nossa área não tem “metodologia genuína” (Dix, 2013, p. 23) ou um "procedimento metodológico que a vertebre univocamente” (Silveira, 2016, p. 75). Como contraponto a essas visões, o presente trabalho objetiva descrever e refletir sobre os métodos próprios desenvolvidos por cientistas das religiões.

Em primeiro lugar, deve-se ter em mente que não está em foco uma discussão sobre se a ciência da religião deve ou não ter somente um método "genuíno” ou central para se constituir enquanto disciplina autônoma. Reconhecemos que existe uma série de técnicas de pesquisa nascidas ao longo desses mais de 150 anos da existência da ciência da religião enquanto área acadêmica institucionalizada. Tais métodos, como em qualquer outra ciência, foram inspirados por métodos anteriores, e depois adaptados ao estudo de seu objeto específico, que são as religiões.

Em segundo lugar, contrapomo-nos à declaração de que “discussões sobre métodos e metodologias são raras na ciência da religião, seja no Brasil, seja no exterior” (Engler, Stausberg, 2013, p. 63). Concordamos que ter mais debates metodológicos nunca é demais. Todavia, não somos tão pessimistas quanto Engler e Stausberg. Os autores clássicos da ciência da religião - principalmente Müller, Tiele e Chantepie De La Saussaye - desenvolveram discussões metodológicas já no século XIX. Mostrar essa nova ciência como autônoma em relação a outras, que "anda com as próprias pernas”, tanto em termos teóricos quanto metodológicos, foi recorrente na Europa desde suas primeiras décadas (Waardenburg, 1999). Os pais fundadores da ciência da religião convenceram um grande público, gerando não apenas publicações, como permitindo a institucionalização universitária da ciência da religião; por vezes sob o título de história das religiões, por vezes como religiões comparadas (Usarski, 2013, p. 56-59).

Essas reflexões continuaram ao longo dos anos, adentrando a segunda corrente teórica-metodológica que predominou o campo: a fenomenologia da religião. Após 1950, no pós Segunda Guerra Mundial, esses debates foram reforçados, principalmente a partir da "briga de métodos” entre a fenomenologia da religião e quem advogava por 
metodologias mais naturalistas/materialistas. Nas últimas décadas, alguns exemplos internacionais mostram, inclusive, uma preocupação cada vez maior frente às questões metodológicas na área. O manual de pesquisa em ciência da religião de Greschat (2005 [1998]), a revista Method and theory in the study of religion, que publica textos específicos dessas temáticas desde 1989, e o The Routledge handbook of research methods in the study of religion (Stausberg, Engler, 2011) são alguns exemplos disso.

Contudo, essa não é uma exclusividade do cenário estrangeiro. No Brasil, a revista Paralellus, do PPG em ciências da religião da UNICAP, organizou dois dossiês sobre métodos, técnicas e tendências de pesquisa em estudos de religião (cf. Paralellus, 2015; 2016). Anos antes, uma postagem publicada no blog desse mesmo PPG abordou novos métodos em ciência da religião ( $c f$. Aragão, 2011). Na UEPA também ocorreu o III Colóquio do Programa de Pós-Graduação em Ciência da Religião e da Jornada Acadêmica da Licenciatura em Ciência da Religião, em novembro de 2016, com o tema “métodos e metodologias na ciência da religião” (Martins, 2016).

Nesse sentido, em reconhecimento da importância de que cientistas das religiões se apropriem das discussões metodológicas de sua disciplina, algumas das principais vertentes nativas da área serão apresentadas nesse artigo, agrupadas em subtópicos de grandes temas-chave nas pesquisas de ciência da religião. Para isso, uma revisão bibliográfica foi realizada, com autores que escreveram dentro de genealogias intelectuais que trataram a ciência da religião enquanto área autônoma. O texto está dividido em quatro grandes temas metodológicos comuns à disciplina: (1) métodos empíricos, (2) métodos comparativos, (3) métodos classificatórios, e um último grupo que chamamos de (4) atitude metodológica frente ao objeto. Em cada seção, a discussão é aprofundada através da revisão bibliográfica sob o recorte específico adotado.

\section{MÉTODOS EMPÍRICOS}

Segundo Teixeira (1989), a universidade moderna surgiu de um rompimento com a estrutura escolástica medieval, buscando abordagens mais experimentais que propiciassem um conhecimento renovado. Universidades alemãs, holandesas, inglesas, francesas e estadunidenses do início do século XIX foram palco desse renascimento 
acadêmico. Friedrich Max Müller (1823-1900), o fundador formal da ciência da religião, estudou durante esse novo contexto que favorecia as fontes empíricas.

Müller aprendeu línguas clássicas e se doutorou em filologia pela Universidade de Leipzig em 1843. Em seguida, estudou filosofia (em especial, a Naturphilosophie) e mitologias com Friedrich Schelling, filologia comparada em Berlim com Franz Bopp, e sânscrito com Eugène Burnouf na França. Mais tarde, apresentou suas pesquisas na Inglaterra, em inglês (Waardenburg, 1999, p. 85; Capps, 1995, p. 65).

Nessa época havia forte referência ao darwinismo nas mais diversas áreas do conhecimento, e prosperava o historicismo alemão, com intensa valorização de fontes primárias, pesquisa indutiva e a busca por compreensão (verstehen) ao invés de explicações quantificáveis (erklären). Isso impactou na formação da ciência da religião, que no entendimento de Müller (1882, p. 26, tradução nossa) deveria estudar "as principais religiões do mundo em seus documentos originais”, ou seja, os escritos das religiões, entendidos por Müller como fontes empíricas seguras.

Várias obras do início da ciência da religião se focaram em registrar essas escrituras sistematicamente ${ }^{3}$. Cornelis Petrus Tiele (1830-1902) e Pierre Daniël Chantepie De La Saussaye (1848-1920), dois outros fundadores dessa nova ciência, seguiram esse espírito de estudos empíricos de documentos religiosos. Assim, essa abordagem se tornou um paradigma metodológico ainda na fase formativa da ciência da religião. Não por acaso, a noção de que fontes empíricas são os livros das religiões perpetuou pela segunda fase de nossa disciplina, quando predominaram as teorias fenomenológicas (Waardenburg, 1999).

Pode-se dizer que pesquisa empírica era sinônimo de pesquisa documental no primeiro século da ciência da religião. Logo, os métodos empíricos se referiam a um paradigma metodológico textual. A formação tradicional de cientistas das religiões é focada no conhecimento da língua das tradições religiosas, para dominar a compreensão de seus textos de maneira filológica e histórica (Eliade, 1989 [1969], p. 79). Até hoje isso ainda ocorre em alguns países, como na Alemanha, onde a área se desenvolveu relativamente cedo (Usarski, 2006, p. 77), e na Dinamarca, onde ela foi constituída tardiamente (Jensen, 2002).

\footnotetext{
${ }^{3}$ P. ex. Sacred books of the East, organizado originalmente por Müller desde 1879.
} 
Todavia, críticas surgiram após a Segunda Guerra Mundial (1945), e conectada a isso, a “briga de métodos” entre os defensores das abordagens fenomenológicas e os defensores de abordagens mais indutivas/históricas para a ciência da religião. Uma delas dizia respeito à necessidade metodológica de valorizar outras fontes empíricas, que não fossem meramente textuais ou relatos indiretos, sobretudo as pessoas religiosas. Nessa discussão, Wilfred C. Smith (1959) sugeriu repensar o modo impessoal norte-americano e europeu de pesquisar religiões, propondo o reconhecimento de que o estudo das religiões é, a princípio, o estudo de pessoas. Na leitura de Greschat (2005, p. 80), Smith realizou uma personalização da ciência da religião, o que levou a duas consequências metodológicas: (1) deixou mais claro o caráter empiricamente humano do seu objeto aos cientistas das religiões, e (2) favoreceu novas perguntas sobre o significado dos textos e demais elementos religiosos para os próprios fiéis.

Desde então, vários cientistas das religiões de todo o mundo têm buscado novas formas de pesquisa empírica não documental. Se, por um lado, métodos exógenos à disciplina, mas consagrados em outras áreas (p. ex. etnografia e modelos de entrevistas) foram cada vez mais tomados de empréstimo, por outro perspectivas metodológicas próprias de cientistas das religiões começaram a surgir. Um exemplo é a categoria de religião vivenciada (lived religion) como método de observação de práticas religiosas, apresentada por vários autores em um livro editado por David Hall (1997).

Também pensando no estudo das pessoas, em sentido mais corporal, incluindo o uso e significados de objetos religiosos, a abordagem materialista não reducionista do cientista das religiões Manuel Vásquez (2011) tem chamado à atenção. Sua proposta radicaliza, em termos empíricos, a percepção de que pessoas religiosas incorporam (embody) visões de mundo, indicando que pesquisas sobre religiões devem dar mais atenção à cultura material religiosa, para entenderem mais profundamente os processos dinâmicos de criação humana de sentidos.

Destaca-se também o desenvolvimento de métodos empíricos pelo cientista das religiões brasileiro Rafael Shoji (2007), quem aborda o que ele chama de "modelos formais”, “parametrizáveis” de formas mais padronizadas e quantificáveis, que também ajudam a entender aspectos culturais qualitativos. Baseado na noção de gramática na linguística de Chomsky e seus desdobramentos nas ciências sociais, essa metodologia 
possibilita encontrar elementos estruturais e dinâmicos em altares religiosos. Além disso, fornece uma série de direcionamentos para estudos de redes religiosas virtuais.

É evidente que há muitos outros métodos de pesquisa empírica desenvolvidos pela ciência da religião ${ }^{4}$. Em geral, o que desejamos destacar é que atualmente, na ciência da religião, seu pilar de pesquisa indutiva cada vez mais se afasta dos estudos textuais, como proposto por seu fundador, em direção aos estudos de pessoas e os significados que elas desenvolvem culturalmente com os elementos religiosos.

\section{MÉTODOS COMPARATIVOS}

A realização de comparações, identificando diferenças e semelhanças entre dois ou mais objetos, perpassa a história da humanidade. No século XIX, comparações foram cada vez sendo mais utilizadas pela ciência empírica experimental, fomentada pelos encontros culturais que se intensificavam devido às ações colonialistas europeias. A noção de evolução foi atrelada a esse modelo, e muitas ciências que estavam nascendo nesse período, como a etnologia/antropologia e a psicologia, começaram a utilizar comparações evolucionistas. Com a ciência da religião isso não foi diferente.

Em seu período inicial, havia um entendimento de que a ciência da religião deveria classificar e comparar os documentos religiosos do mundo. Müller (1882, p. 9, tradução nossa) acreditava que "todo conhecimento mais elevado é adquirido por e se baseia em comparação”. Assim, se cientistas das religiões empregassem um método comparativo, sua ciência teria uma base científica e verdadeira pelos parâmetros de Müller (1882, p. 26).

Inicialmente a comparação foi entendida dentro de uma perspectiva indutiva que valorizava a análise das fontes primarias, marcada pelo historicismo alemão. Ao mesmo tempo, tanto estudos históricos particulares como pesquisas comparativas buscavam por possíveis “leis universais” de causa e efeito, através da comparação de evidências, com forte influência do darwinismo (Sharpe, 1986, p. 29-31). Este método foi utilizado desde o início da ciência da religião, tornando-se o paradigma metodológico dominante até o início do século XX (Waardenburg, 1999; Sharpe, 1986).

\footnotetext{
${ }^{4}$ Uma série de métodos empíricos para o estudo de pessoas religiosas, visualidades e objetos materiais religiosos é descrita na segunda parte do livro The Routledge handbook of research methods in the study of religion (cf. Stausberg, Engler, 2011).
} 
Rompendo parcialmente com as atitudes preconceituosas anteriores, e buscando encontrar a "essência” das religiões em suas manifestações, a corrente fenomenológica da ciência da religião foi criada. Chantepie De La Saussaye (1891, p. 67-242; 1940), seu formulador, pensou a fenomenologia da religião como uma abordagem para organizar e sistematizar os dados levantados pela história de religiões específicas. Por isso, até hoje o termo "fenomenologia da religião" é confundido, por vezes, com a comparação descritiva de religiões (Hock, 2010).

Conforme esse autor, a sistematização de dados religiosos deveria ter como foco a consciência (ou "processos internos”) das pessoas religiosas, próximo a uma visão psicológica, sendo esse o eixo para realizar as comparações. No início do século XX, os autores que desenvolveram a abordagem fenomenológica clássica (p. ex. Otto, Wach e van der Leuuw) passaram a utilizar as expressões "experiência religiosa”, "experiência do sagrado" e termos afins como foco de seus estudos.

Seguindo a proposta epistemológica de compreender (verstehen), esses estudos começaram a se organizar em modalidades de experiências, buscando entender e ordenar as vivências internas por suas expressões externas. Partindo do pressuposto de que as religiões manifestam uma "essência”, seus teóricos inventaram categorias morfológicas para agrupar e comparar os dados religiosos. Por exemplo, divindades entendidas como de um mesmo tipo (do céu, da terra, da lua, das matas), mesmo que provenientes de tradições díspares, foram estudadas em um mesmo eixo morfológico.

Uma dos que mais obteve destaque mundial utilizando os métodos comparativos foi Mircea Eliade (1907-1986), em continuação ao legado de Joachim Ernst Adolphe Felix Wach, na Universidade de Chicago. Filósofo de formação, Eliade foi um cientista das religiões autodidata, compreendendo a ciência da religião como a área responsável por integrar academicamente todo material religioso, o que exige, na prática, um domínio enciclopédico, erudito e sempre atualizado de seus pesquisadores. Sua obra mais exemplar utilizando esse método é o Tratado de História das Religiões (Eliade, 1998 [1949]). Nesse livro, a morfologia iniciada por cientistas das religiões de linha fenomenológica anteriores a ele, somada a referências outras, ganhou um aspecto mais aprofundado de generalização hermenêutica.

No que concerne ao empréstimo de métodos de outras ciências, Eliade (1989 [1969], p. 83) enfatizava que o que importa ao cientista das religiões é “a sua liberdade 
de expressão" diante da pesquisa das mais variadas manifestações religiosas, não sendo o pesquisador obrigado a "buscar nem os métodos de um filósofo contemporâneo, nem a perspectiva ou linguagem da psicologia, da antropologia cultural ou da sociologia”. Se não é obrigado a buscar métodos de outras áreas, qual metodologia utilizar então?

Eliade (1989 [1969]) era enfático em defender uma hermenêutica total baseada em outros cientistas das religiões, como Petazzoni e van der Leeuw, método que consistia em generalizações compreensivas de sentidos humanos profundos por comparações de materiais religiosos estudados historicamente. Ou seja, uma integração de pesquisas históricas em religiões específicas com estudos que comparam esses dados particulares, cuja integração deve fazer surgir generalizações criativas e inovadoras para as culturas humanas atuais, e não só academicamente. Essa abordagem se tornou um paradigma mundialmente seguido durante a segunda fase da ciência da religião mundial, tendo forte presença em certos círculos acadêmicos até hoje, como nas graduações em ciência da religião do Brasil.

Com esse método, apesar da referência a fontes históricas, muitas comparações foram feitas entre tradições que tinham elementos que, em sua forma, eram parecidos, mas sem conexão histórica. Surgiram, assim, críticas de que certas comparações eram generalizações arbitrárias, baseadas na visão pessoal do pesquisador. É o caso de certos padrões de homologias e analogias (p. ex. “deuses celestiais”, “simbolismo da água”, “pedras sagradas”) levantados por Wach, van der Leeuw e Eliade (Martin, 2000, p. 52).

Rafaelle Petazzoni (1883-1959), o fundador da ciência da religião na Itália, foi um dos primeiros a perceber a fragilidade dessa abordagem clássica da fenomenologia, optando por uma visão mais historicista das religiões. Seu método comparativo se baseou em autores da primeira fase da ciência da religião, em especial de Müller, mas indo além deles. Para Petazzoni (2016), toda comparação sempre deve estar contextualizada e não pode ser uma abstração morfológica descolada de fatos históricos. Petazzoni (2016) entendia que todo fenômeno é fruto de formações históricas, surgindo com processos de desenvolvimentos materiais. Com essa visão, ele criou um paradigma paralelo à fenomenologia clássica, deixando claro o limite metodológico da ciência da religião e fortalecendo sua autonomia frente a outras disciplinas, sobretudo à teologia.

Desde então, outros cientistas das religiões continuam a propor metodologias comparativas, como Jan G. Platvoet (1982), Hans-Jürgen Greschat (2005), Arvind 
Sharma (2005), e Michael Pye (2013). Mas foi na década de 1990 que uma nova perspectiva para os métodos comparativos, que tem se destacado internacionalmente, surgiu na ciência da religião: o novo comparativismo (Martin, 2000, p. 52-55).

O novo comparativismo seria um retorno à busca iluminista por dados humanos universais, mas retirando as bases teológico-metafísicas descontextualizadas (como a noção de um suposto "sagrado” comum às religiões). Baseado em teorias naturalistas, de ciências cognitivas, neurociências, arqueologia e evolucionismo biológico, esse método observa estruturas-padrão biológicas e culturais possíveis de serem estudadas mais formalmente. O entendimento de que as religiões são socialmente construídas é integrado à percepção de que a cultura também é uma adaptação de padrões biológicos comuns à humanidade. Sendo assim, pesquisadores como William E. Paden (2016) têm apontado para uma nova tradição fenomenológica que se nutre desse método inovador de comparação das religiões.

Para concluir esse tópico, é importante ressaltar que há vários métodos de comparar religiões, e que na verdade a comparação em si é muito mais um modelo de pesquisa, com diferentes possibilidades metodológicas (Stausberg, 2011). Martin (2000, p. 48) recorda que no $10^{\circ}$ Congresso da IAHR, em 1960, foi descrito que, dentre as pressuposições básicas para a ciência da religião, está a de se fazer generalizações cientificamente legitimadas sobre a natureza e função das religiões. Baseado em Jonathan Z. Smith, Martin (2000) lembrou que a própria noção de religião pode ser lida como um ato de comparação e generalização de teóricos. Sendo assim, comparar é uma tarefa que constituí a própria estrutura da ciência da religião, seja de maneira clássica, histórico-filológica, ou seja pelo novo comparativismo.

\section{MÉTODOS CLASSIFICATÓRIOS}

Ao longo da história da ciência da religião, a classificação dos diferentes tipos de religiões assumiu papel central na construção do conhecimento e no avanço da área internacionalmente. Segundo Hock (2010, p. 96-97), ao se depararem com a diversidade religiosa, os primeiros cientistas das religiões perceberam a necessidade de identificar características que lhes eram compartilhadas, o que permitiu classificá-las em grupos. São os métodos classificatórios que possibilitam, por exemplo, que uma religião seja 
identificada como monoteísta, henoteísta ou politeísta, ou que categorias relacionadas às religiões sejam agrupadas em tipológicos como "mística”, “seita”, “ritual”, "bênção”, “oração”, “maldição”, “milagre”, “tabu” etc.

Cornelis P. Tiele (1884), um dos fundadores da ciência da religião na Europa, em sua proposta de classificação traçou a distinção básica entre "religiões naturais” e "religiões éticas", e dentre esse último grupo, uma segunda divisão entre "religiões nacionais” e "religiões universais”. Essa noção de religiões éticas universais se tornou um paradigma para a ciência da religião, popularizando-se para além de seu domínio ${ }^{5}$, tendo respaldo em outras áreas ${ }^{6}$ (Smith, 2000, p. 42).

Os métodos classificatórios são muito caros, em especial, à subdisciplina de ciência sistemática das religiões e à fenomenologia da religião (Greschat, 2005, p. 136). Assim como os métodos comparativos, as pesquisas classificatórias são de natureza majoritariamente descritiva. Historicamente esses métodos foram desenvolvidos com base nas taxonomias das ciências biológicas, embora os resultados apresentado nas pesquisas de cientistas das religiões sempre tenham um caráter mais filosófico do que o dos modelos da biologia (Smith, 2000, p. 37).

Segundo Greschat (2005, p. 136), as pesquisas que utilizam o método classificatório em ciência da religião usualmente são divididas em duas etapas: (1) uma primeira fase tipológica, que diz respeito à identificação e explicação das categorias que ordenarão o que será investigado no campo religioso, e (2) uma fase posterior, mais longa, que visa descrever o mais completamente possível cada um dos tipos elencados na primeira fase.

Já no século XIX, Chantepie De La Saussaye (1940 [1887], p. 16-17) identificou dois tipos principais de metodologias classificatórias das religiões: (1) as classificações genealógicas, baseadas em troncos linguísticos, históricos, étnicos ou geográficos (p. ex. religiões semíticas, indianas, nórdicas); e (2) as classificações morfológicas, cujas categorias são criadas pelo próprio pesquisador, visando responder seu problema de estudo (p. ex. religiões populares e religiões de fundadores, ou religiões naturais e religiões reveladas). É evidente que esses dois tipos não esgotam as possibilidades de métodos classificatórios, conforme o próprio Chantepie De La Saussaye deixou claro

\footnotetext{
${ }^{5}$ P. ex. a utilização do termo "religiões mundiais” pelo Parlamento Mundial das Religiões, de 1893, em Chicago, EUA.

${ }^{6}$ P. ex. na concepção de “religiões mundiais” no pensamento de Max Weber e de Ernst Troeltsch.
} 
em seu texto, mas representam o que esse autor identificou como sendo os tipos mais comuns de classificações feitas na fase inicial da ciência da religião.

As classificações morfológicas, conforme explica Chantepie De La Saussaye (1940 [1887], p. 17), acabam sendo menos objetivas do que as classificações genealógicas, pois as apreciações pessoais podem fazer com que outros cientistas das religiões, ao tentarem reaplicar o mesmo método, discordem do que o pesquisador anterior compreendeu originalmente por cada tipo. Ao passo que classificar as religiões como "chinesas" ou "africanas” (classificação genealógica) tende a encontrar menores questionamentos, classificar uma religião como "natural” ou "relevada”, por exemplo, pode encontrar divergências, visto a polissemia de seus epônimos. É por isso que é unânime, entre os que comentam os métodos classificatórios das religiões, que nunca houve uma tipologia que pudesse ser totalmente aceita (Chantepie De La Saussaye, 1940 [1887], p. 15; Greschat, 2005, p. 142; Hock, 2010, p. 99).

Outra característica interessante das pesquisas em ciência da religião que empregam os métodos classificatórios é a pluralidade de referências às quais recorrem. Fontes que são aparentemente desconexas, ou que seriam até mesmo consideradas irrelevantes pelos critérios de outras ciências humanas, costumam ser abundantemente mencionadas nesses trabalhos, mas sem um aprofundamento maior do que uma breve menção pelos cientistas das religiões que as citam. Greschat (2005, p. 137-140) atenta a essa característica ao comentar os trabalhos de Gerardus van der Leeuw, Friedrich Heiler e Geo Widengren. Isso se justifica porque o foco nos estudos classificatórios de religião não está na historiografia de cada uma das fontes, nem mesmo na investigação de cada contexto religioso ou cultural do qual derivam, mas em um aprofundamento substancial da tipologia desenvolvida pelo cientista das religiões. Logo, as fontes servem apenas como exemplos ao que o pesquisador definiu em cada categoria.

Por conta disso, conforme descreve Greschat (2005, p. 140-141), esse método tende a ignorar a localização histórica do fenômeno estudado, visto buscar apenas o que considera essencial à categoria analisada, de forma transcultural. Greschat (2005, p. 139-140) ilustra isso explicando o trabalho de Widengren:

O tema "tabu", por exemplo, ocupa onze páginas [de sua obra]. Nesse artigo Widengren fala sobre os polinésios, o povo queniano dos kikuyus e os semitas; cita teóricos como Rudolf Lehmann, A. R. Radcliffe-Brown ou W. Robertson Smith e analisa as múltiplas regras de tabus seguidas pelos Flamen Dilis, sacerdotes romanos que louvavam o deus Júpiter, e pelos 
brâmanes hindus. Descreve a importância dos tabus para comunidades como a dos sacerdotes do deus Zeus em Dodona, Grécia, a dos recabitas mencionados no Antigo Testamento ou a dos pitagóricos. Aponta para o fato de que os peregrinos submetam-se temporariamente a regras de tabu. [...] Finalmente, o artigo [apresenta] uma síntese dos conceitos de tabu defendidos por outros cientistas.

É importante ressaltar que como o objetivo desse método é a criação e compreensão de categorias sistemáticas que organizam dados observados em trabalhos de especialistas (Hock, 2010, p. 76), as pesquisas classificatórias das religiões são estudos qualitativos por natureza. Isso por vezes não fica claro aos estudiosos de metodologias em ciência da religião, visto os autores clássicos que desenvolveram esse método apresentarem-no em obras demasiadamente longas e, por vezes, citarem muitos números. Conforme mencionou Greschat (2005, p. 141), o livro de van der Leeuw possui 800 páginas, o de Heiler 600 páginas, e o de Widengren 680.

Há muitas críticas - tanto externas quanto internas à ciência da religião - aos métodos classificatórios nos estudos das religiões, visto que historicamente eles foram utilizados, muitas vezes, adotando ou promovendo concepções colonialistas (e até mesmo preconceituosas) das religiões que estavam sendo classificadas. Todavia, Smith (2000, p. 43) considera que, para além das críticas que alguns métodos classificatórios justamente merecem, o processo de se classificar as coisas é uma atividade mental cognitiva importante, e que rejeitar as classificações como um todo seria rejeitar o ato de pensar em si, ratificando a importância dessa metodologia para o campo atual da ciência da religião.

Alguns exemplos de métodos classificatórios que nasceram nas últimas décadas são: a proposta de professores do departamento de ciência da religião da Universidade de Lancaster, que divide as religiões contemporâneas entre "religiões de diferença”, “religiões de humanidade” e “espiritualidades de vida” (cf. Woodhead, Heelas, 2000); a distinção de Wouter J. Hanegraaff (1999) entre "religião (geral)”, “uma religião (específica)” e “espiritualidade”; a classificação de seis dimensões presentes em todas as religiões, o que foi aumentado para sete (como é mais conhecido) e, por último, para oito, proposto por Roderick Ninian Smart (1973; 1996); e o método de identificação de religiões implícitas/seculares de Jonathan Benthall (2008) através de 19 categorias de análise. 


\section{ATITUDE METODOLÓGICA FRENTE AO OBJETO}

Para além dos métodos mencionados, uma característica muito importante das pesquisas em ciência da religião, por afetar diretamente o resultado das investigações acadêmicas, é sua atitude frente ao objeto. Esse é seu grande diferencial quando em comparação com outras áreas que também estudam religiões, como a teologia e, em grande parte, a filosofia. Desde seu fundador há a preocupação em não cair em visões parciais no estudo sobre religiões (Müller, 1882), e isso foi colocado em vários termos ao longo da história. Internacionalmente as discussões atuais por trás dessa categoria podem ser classificadas em dois grandes grupos interpendentes: (1) a distinção entre a perspectiva êmica e a perspectiva ética ${ }^{7}$, e (2) a adoção do agnosticismo metodológico.

A distinção entre êmico e ético para a ciência da religião foi proposta por Jan G. Platvoet (1982, p. 5-6; 21, 29), quem classifica a abordagem êmica como sendo a visão de dentro da religião, comumente etnocentrada e proselitista ao lidar com perspectivas de outras confissões, ao passo que a abordagem ética é a das categorias acadêmicas, fundamentadas nas teorias que permitem um exame analítico, com olhar que estuda as religiões de fora. Como o discurso êmico denota o paradigma intersubjetivo dos fieis, a perspectiva de quem crê, constitui fonte de pesquisa importante a qualquer estudo sobre religiões. Mas na ciência da religião, as construções devem se pautar na abordagem ética, ou seja, no crivo analítico a partir das categorias (históricas, sociais, políticas, culturais, psicológicas, comparativas, econômicas etc.) elencadas para a pesquisa.

Ainda que o próprio Documento da Área de Avaliação 44 na CAPES, relativa ao campo da ciência da religião e da teologia, descreva cientistas das religiões como aqueles que estudam "o fato religioso, a experiência religiosa, os fenômenos, as experiências, os conteúdos, as expressões, os textos, as tradições, as linguagens, as culturas religiosas e as tradições de sabedoria, considerados em perspectiva externa"8 (CAPES, 2016, p. 9, grifo nosso), muitas pessoas buscam a ciência da religião no Brasil como forma de legitimar seu próprio discurso êmico, sem maiores preocupações com a abordagem ética. Em outras palavras, fazer ciência para a religião, e não ciência sobre religiões. O fato de a maioria das pessoas pesquisar sua própria confissão piora

\footnotetext{
${ }^{7}$ Sem qualquer relação com a categoria “ética” da filosofia.

${ }^{8}$ Ou seja, examinados pela abordagem ética, de acordo com a distinção entre êmico e ético proposta por Platvoet, embora as palavras “ético” e “êmico” não sejam objetivamente encontradas no documento.
} 
bastante esse quadro. Não por acaso, abrem-se margens para estranhamentos com a proposta do agnosticismo metodológico, internacionalmente uma das especificidades acadêmicas da ciência da religião.

O agnosticismo metodológico se refere à postura da ciência da religião de excluir de seus estudos a questão da "verdade última". O termo foi cunhado pelo cientista das religiões Roderick Ninian Smart (1973, p. 54-57), em seu comentário ao texto de Peter Berger (1985, p. 112, 186), O Dossel Sagrado, sugerindo que a utilização do ateísmo metodológico proposto por Berger não seria a abordagem mais apropriada a cientistas das religiões. Smart (1973, p. 54, 57-58) defende que o agnosticismo metodológico é uma postura intermediária mais coerente entre a prerrogativa da existência de Deus, tal qual feito pela teologia, e uma pré-concepção de que Deus não existe, como ele entendeu que Berger propunha.

Segundo Cruz (2013, p. 44), como a dimensão metaempírica ou sobrenatural das religiões não pode ser acessível ao método científico, os cientistas das religiões nada têm a comentar a seu respeito. A ciência da religião deve examinar as religiões como construções sociais, desconsiderando as alegações de seus adeptos de que suas crenças são revelações divinas. Isso, todavia, não deve ser interpretado como uma licença para que os cientistas das religiões julguem a validade do discurso êmico, pois não é essa a incumbência de nossa ciência.

Quando Platvoet (1982, p. 4-7) explica o diferencial da Religionswissenschaft na Alemanha, ele considera que a parte “científica” da ciência da religião jaz justamente em sua preocupação com a objetividade acadêmica. Assim, o autor elenca três pontos sobre como se articula a objetividade entre cientistas das religiões: (1) o reconhecimento de que há uma variedade cultural imensa de religiões, e que nenhuma pesquisa poderá ser objetiva a menos que quem pesquise seja capaz de excluir toda postura normativa e julgadora inculcada por sua própria cultura e religião; (2) a inserção da abordagem ética enquanto metodologia de análise dos conteúdos êmicos que emergem do campo; e (3) a apresentação dos resultados de maneira distanciada e coerente, que permita verificação total dos métodos empregados, das teorias realizadas e dos dados encontrados durante a pesquisa por outros cientistas das religiões.

Em outras palavras, cientistas das religiões assumem, através do agnosticismo metodológico, uma postura epistemológica específica, baseada em um compromisso 
com um ideal de "indiferença” frente às questões dogmáticas e de juízos de valor, limitando-se aos aspectos materiais e históricos do que pode ser entendido como religioso (Usarski, 2013, p. 51). Ao invés de discutir a existência ou não de uma ou mais divindades, ou a validade de um ou outro comportamento religioso, cientistas das religiões se focam nos elementos das religiões acessíveis empiricamente, evitando discussões que estão para além do método científico. Seu objetivo é conhecer sobre o fato da vida religiosa, sem apologias a uma crença determinada. Na ciência da religião, as verdades últimas (p. ex. a existência de Deus) são postas de lado, sem uma preocupação em negá-las ou afirmá-las. Tanto que quando um pesquisador não consegue fazer isso, é comum que sua postura seja denunciada como criptoteologia ou prototeologia no campo da ciência da religião ${ }^{9}$.

Porém, esse é um tema longe de estar resolvido, visto causar muito desconforto entre os adeptos/insiders. Nas palavras de Cruz (2013), não basta que um cientista das religiões declare que

[...] "os cristãos consideram que Jesus Cristo é Filho de Deus” como parte da realidade cultural, e tirar consequências daí, mas precisa enfrentar continuamente a afirmação dos cristãos de que "Jesus Cristo é Filho de Deus”, como parte da realidade objetiva (p. 44, grifo do autor).

Por isso, é comum que aqueles que estudam sua religião emicamente, de dentro, critiquem o agnosticismo metodológico, declarando que ele não atinge a neutralidade a qual se propõe. O filósofo Michael A. Cantrell (2016, p. 385), por exemplo, declara que assim como o solipsismo implícito no ateísmo metodológico revela apenas o mundo como ele é, o agnosticismo metodológico sistematicamente ignora o significado moral e existencial da relação da pessoa com Deus, defendendo que seria uma obrigação de todo pesquisador das religiões abordar a questão moral.

No Brasil, o filósofo Luiz Felipe de Cerqueira e Silva Pondé é um dos que também criticaram o agnosticismo metodológico. Pondé (2001, p. 42, 45) considera que se o espiritual for excluído da ciência da religião, seu objeto sofre uma "lobotomia", declarando que o agnosticismo metodológico seria um sintoma da falta de "tato religioso”. Pondé (2001, p. 55) questiona se não “seria razoável supor que indivíduos desprovidos do 'tato religioso' seriam como cegos tentando descrever a natureza do vermelho”. Para Pondé (2001, p. 56-70), quem adota o agnosticismo metodológico tem

\footnotetext{
${ }^{9}$ Para alguns exemplos, cf. Engler (2004, p. 31, 39), Usarski (2006, p. 36-37) e Cruz (2014, p. 41).
} 
pavor de adentrar nos campos da experiência religiosa, separando o campo entre os insiders e os empiristas que "os perseguem” (sic.).

Apesar de críticas similares serem citadas como justificativas por brasileiros que querem estudar suas próprias confissões religiosas pela perspectiva êmica, deve-se ter claro que nem Cantrell nem Pondé são cientistas das religiões. Cantrell é filosofo, seu escopo metodológico está alinhado à filosofia, e o principal objeto de estudo de sua carreira é o papel e a importância da religião para a área da filosofia, com o foco sempre no filósofo, e não no cientista das religiões. Já a crítica de Pondé não cita qualquer exemplo empírico do que ele considerou como sendo "pavor de experiências religiosas”, o que torna sua argumentação mera retórica. Ele também não publicou pesquisas sociais empíricas sobre religiões, o que levanta a seguinte questão: como alguém que nunca utilizou um método pode dizer que ele não funciona ou que é inválido? Além disso, embora seja docente de um programa de ciência da religião, Pondé continuamente afirma que seus trabalhos são da área da filosofia.

Ter isso em mente facilita entender as explicações que os próprios cientistas das religiões fornecem sobre o porquê de tais críticas não fazerem muito sentido para a nossa área, embora talvez possam ser pertinentes aos estudos sobre religião na filosofia. O cientista das religiões Zeba Crook (2016 apud Sheedy, 2016, p. 296), comenta que

uma zoóloga não pergunta a um elefante como é ser elefante; ela estuda o elefante. Um biólogo não tenta imaginar a experiência de um sapo antes de dissecá-lo e tentar entender como ele funciona. As religiões podem ser estudadas analiticamente, eticamente, de fora, como em qualquer outra disciplina analítica. Elas também podem ser estudadas como um membro, adepto e praticante, honrando as experiências de seus companheiros simpatizantes e suas reivindicações internas de autoridade. Mas essa é uma disciplina totalmente diferente da ciência da religião. Não se trata de neutralidade, mas de fronteiras disciplinares.

Segundo Crook (2016 apud Sheedy, 2016, p. 299), cientistas das religiões não deveriam operar diferente dos cientistas de outras disciplinas. A justificativa de que seu objeto é “diferente” não basta. Há objetos de pesquisa esquivos em outras áreas ${ }^{10}$, e nem por isso elas recorrem a abordagens metacientíficas. Considerar a priori que quem não é “sensível” para perceber manifestações do espiritual não pode estudar academicamente

\footnotetext{
${ }^{10}$ Citando um exemplo, é muito difícil pesquisar sentimentos. Contudo há todo um ramo da psicologia focado em quantificar emoções e outros aspectos psicológicos, tratando os sentimentos com o mesmo rigor científico que qualquer outro objeto. Quem trabalha com psicometria não precisa sentir o que seus sujeitos de pesquisa estão sentido para conseguir fazer ciência.
} 
religião ou que todo estudioso das religiões deve se debruçar sobre a moral religiosa demonstra uma questão de fé que está para além do que uma ciência pode, de fato, verificar. A utilização da perspectiva ética e a adoção do agnosticismo metodológico são condições sine quibus non para cientistas das religiões realizarem seu trabalho.

\section{CONCLUSÕES}

O presente estudo identificou uma série de métodos formulados por cientistas das religiões ao longo da história da sua disciplina, organizados em quatro tipos principais de abordagens metodológicas. Ainda que muitos deles não sejam exclusivos da ciência da religião e derivem de fontes anteriores, isso não os invalida como construções de técnicas de pesquisa próprias da genealogia intelectual dessa área - até porque com outras ciências ocorre o mesmo. O conhecimento dessa parte metodológica da identidade historicamente estabelecida pela ciência da religião reforça que essa ciência não se trata de uma mera “colcha de retalhos”. Mesmo sendo plurimetodológica, a ciência da religião tem suas próprias regras de pesquisa.

Entende-se que a ideia equivocada de que faltam métodos na ciência da religião pode ser resultado de muitas causas. Algumas possibilidades seriam: (1) uma falha no ensino dessa disciplina no Brasil, que pouco aborda em seus currículos a sua história internacional; (2) o fato da maioria dos docentes serem formados em outras áreas; e (3) seus pesquisadores em nível de pós-graduação geralmente derivarem de graduações que não a própria ciência da religião. Com observações similares, Engler (2010, p. 276) tem apontado para uma dificuldade da área estabelecer identidade no Brasil.

Buscando superar isso, é sugerido que cientistas das religiões: (1) empoderem-se da história própria da ciência da religião, saindo do conformismo de só conhecerem os autores e técnicas de suas áreas de formação original (no caso das pós-graduações), ou das áreas de formação de seus professores que não são cientistas das religiões de formação; e (2) que tenham mais coragem, ousadia e maior autonomia para desenvolver uma tradição de ciência da religião que não só repita, mas que também crie conhecimentos teóricos e metodológicos próprios, através de uma antropofagia intelectual que absorva as virtudes do saber internacional e o transforme criativamente, integrando-os aos nossos saberes e os adequando ao nosso contexto. 


\section{REFERÊNCIAS}

ARAGÃO, Gilbraz. Novos métodos em ciências da religião. Ciências da religião: bloco de notícias do Programa de Pós-Graduação da UNICAP. Recife, 26 out. 2011. Disponível em: <http://crunicap.blogspot.com.br/2011/10/novos-metodos-em-cienciasda-religiao.html>. Acesso em: 14 ago. 2017.

BENTHALL, Jonathan. Returning to religion: why a secular age is haunted by faith. London: I. B. Tauris, 2008.

BERGER, Peter L. O dossel sagrado: elementos para uma teoria sociológica da religião. São Paulo: Paulus, 1985.

CANTRELL, Michael A. Must a scholar or religion be methodologically atheistic or agnostic? Journal of the American Academy of Religion, Oxford, v, 84, n. 2, 2016, p. 373-400.

CAPES. Ciências da religião e teologia: documento de área. Brasília: MEC, 2016.

CAPPS, Walter H. Religious studies: the making of a discipline. Minneapolis: Fortress, 1995.

CHANTEPIE DE LA SAUSSAYE, Pierre Daniel. Manual of the science of religion. London: Longmans, Green, 1891.

História das religiões. $2^{\mathrm{a}}$ ed. Lisboa: Inquérito, 1940.

CRUZ, Eduardo R. Estatuto epistemológico da ciência da religião. In: PASSO, João Décio; USARSKI, Frank (Org.). Compêndio de ciência da religião. São Paulo: Paulus; Paulinas, 2013, p. 37-49.

DIX, Steffen. O que significa o estudo das religiões: uma ciência monolítica ou interdisciplinar? Revista Lusófona de Ciência das Religiões, Lisboa, n. 11, 2013, p. 11-31.

ELIADE, Mircea. Origens: história e sentido na religião. Lisboa: Edições 70, 1989. . Tratado de história das religiões. São Paulo: Martins Fontes, 1998.

ENGLER, Steven; STAUSBERG, Michael. Metodologia em ciência da religião. In: PASSOS, João Décio; USARSKI, Frank (Org.). Compêndio de ciência da religião. São Paulo: Paulus; Paulinas, 2013, p. 63-73;

ENGLER, Steven. Brazil. In: ALLES, Gregory D. (Ed.). Religious studies: a global view. New York: Routledge, 2010, pp. 273-277.

GRESCHAT, Hans-Jürgen. O que é ciência da religião? São Paulo: Paulinas, 2005.

HALL, David D. (Ed.). Lived religion in America: toward a history of practice. Princeton: Princeton University, 1997. 
HANEGRAAFF, Wouter Jacobus. Defining religion in spite of History. In: PLATVOET, Jan G.; MOLENDIJK, Arie L. (Eds.). The pragmatics of defining religion: contexts, concepts \& contests. Leiden: Brill, 1999, p. 337-378.

HOCK, Klaus. Introdução à ciência da religião. São Paulo: Loyola, 2010.

JENSEN, Tim. O estudo das religiões na Dinamarca. Revista Imaginário, São Paulo, n. 8, 2002, p. 396-418.

MARTIN, Luther H. Comparison. In: BRAUN, Willi; McCUTCHEON, Russell (Eds.). Guide to the study of religion. London: Continuum, 2000, p. 45-56.

MARTINS, Fernanda. Ciência da religião debate métodos e metodologia. Universidade do Estado do Pará, Belém, 16 nov. 2016, Notícias. Disponível em: $<$ http://www.uepa.br/pt-br/noticias/ci\%C3\%AAncia-da-religi\%C3\%A3o-debatem\%C3\%A9todos-e-metodologia>. Acesso em: 14 ago. 2017.

MÜLLER, Max F. Introduction to the science of religion: four lectures delivered at the Royal Institution in February and May, 1870 [New Edition]. London: Longmans, Green \& Co., 1882 [1870].

PADEN, William E. New patterns for comparative religion: passages to an evolutionary perspective. London; New York: Bloomsbury Academic, 2016.

PARALELLUS: Revista de Estudos de Religião da UNICAP. Dossiê: métodos, técnicas e tendências de pesquisa em estudos de religião. Recife, v. 6, n. 13, jul./dez. 2015.

Dossiê: métodos, técnicas e tendências de pesquisa em estudos de religião II. Recife, v. 7, n. 14, jan./abr. 2016.

PETAZZONI, Raffaele. O método comparativo. Religare: Revista do PPG em Ciências das Religiões da UFPB, João Pessoa, v. 13, n. 1, 2016, p. 245-265.

PLATVOET, Jan G. Comparing religions: a limitative approach. Den Haag: Mouton, 1982.

PONDÉ, Luiz Felipe de Cerqueira e Silva. Em busca de uma cultura epistemológica. In: TEIXEIRA, Faustino Luis Couto (Org.). A(s) ciência(s) da religião no Brasil: afirmação de uma área acadêmica. São Paulo: Paulinas, 2001, p. 11-66.

PYE, Michael. Strategies in the study of religions. Berlin; Boston: DeGruyter, 2013.

SHARMA, Arvind. Religious studies and comparative methodology: the case for reciprocal illumination. New York: Suny, 2005.

SHEEDY, Matt. Ateísmo metodológico vs. agnosticismo metodológico. Revista Último Andar, São Paulo, v. 1, n. 29, 2016, p. 295-303. 
SHOJI, Rafael. Estudos formais e modelos computacionais da religião. In: USARSKI, Frank (Org.). O espectro disciplinar da ciência da religião. São Paulo: Paulinas, 2007, p. 232-257.

SILVEIRA, Emerson José Sena da. Uma metodologia para as ciências da religião? Impasses metodológicos e novas possibilidades hermenêuticas. Paralellus: Revista de Estudos da Religião da UNICAP, Recife, v. 7, n. 14, 2016, p. 73-98.

SMART, Roderick Ninian. The science of religion and the sociology of knowledge: some methodological questions. Princeton: Princeton University, 1973.

Dimensions of the sacred: an anatomy of the world's beliefs. Berkeley; Los Angeles: University of California Press, 1996.

SMITH, Jonathan Z. Classification. In: BRAUN, Willi; McCUTCHEON, Russell (Eds.). Guide to the study of religion. London: Continuum, 2000, p. 35-43.

SMITH, Wilfred Cantwell. Comparative Religion: whither - and why? In: ELIADE, Mircea; KITAGAWA, Joseph (Eds.). The history of religion: essays in methodology. Chicago: University of Chicago, 1959, p. 31-58.

STAUSBERG, Michael. Comparison. In: STAUSBERG, Michael; ENGLER, Steven (Eds.). The Routledge handbook of research methods in the study of religion. New York: Routledge, 2011, p. 21-39.

STAUSBERG, Michael; ENGLER, Steven (Eds.). The Routledge handbook of research methods in the study of religion. New York: Routledge, 2011.

TEIXEIRA, Anísio. Ensino superior no Brasil: análise e interpretação se sua evolução até 1969. Rio de Janeiro: Fundação Getúlio Vargas, 1989.

TIELE, Cornelis P. Religions. In: BAYNES, Thomas S (Ed.). Encyclopedia Britannica, 9th edition. London: Encyclopedia Britannica, 1884, p. 358-371.

USARSKI, Frank. Constituintes da ciência da religião: cinco ensaios em prol de uma disciplina autônoma. São Paulo: Paulinas, 2006.

História da ciência da religião. In: PASSOS, João Décio; USARSKI, Frank (Orgs.). Compêndio de ciência da religião. São Paulo: Paulus; Paulinas, 2013. p. 5162.

VÁSQUEZ, Manuel A. More than belief: a materialist theory of religion. Oxford; New York: Oxford University, 2011.

WAARDENBURG, Jacques. Classical approaches to the study of religion: aims, methods and theories of research. Berlim; New York: Walter de Gruyter, 1999 [1973].

WOODHEAD, Linda; HEELAS, Paul Lauchlan Faux. Religion in Modern Times: an interpretive anthology. Oxford: Blackwell, 2000. 